\title{
Erratum to: A case study: travel time inversion for P-wave velocity using OBS data of South China Sea
}

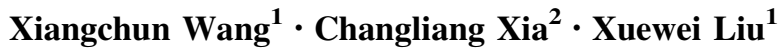

Published online: 30 July 2015

(C) Springer Science+Business Media Dordrecht 2015

\section{Erratum to: Mar Geophys Res (2012) 33:389-396 DOI 10.1007/s11001-013-9167-7}

With this erratum Prof. T. A. Minshull withdraws co-authorship of article 'A case study: travel time inversion for P-wave velocity using OBS data of South China Sea' published in Volume 33, Issue 4, pages 389-396, DOI: 10. $1007 / \mathrm{s} 11001-013-9167-7$ as there is no contribution to the content and writing process of this article from his side. Prof. Minshull was visited by the first author in Southampton who received advice from him, but Prof. Minshull was not consulted at any stage of drafting or submitting the paper. Authors Xiangchun Wang, Changliang Xia and Xuewei Liu apologize for including Prof. T. A. Minshull's name without his knowledge and permission.

The online version of the original article can be found under doi:10.1007/s11001-013-9167-7.

Xiangchun Wang

wangxcqs@126.com

1 Key Laboratory of Geo-detection, Ministry of Education, China University of Geosciences (Beijing), Beijing, People's Republic of China

2 Overseas Business Department of Geophysical Research Institute, BGP Inc. of CNPC, Zhuozhou, Hebei,

People's Republic of China 